\title{
Teaching Piano in China: Building Transcultural and Transhistorical Bridges through Music Education
}

\author{
Hao Huang ${ }^{1} \&$ Tatiana Thibodeaux ${ }^{1}$ \\ ${ }^{1}$ Scripps College, Claremont, CA, USA \\ Correspondence: Hao Huang, Bessie and Cecil Frankel Chair in Music, Senior Advisor to the President for \\ International Initiatives, Scripps College, Claremont, CA, USA.
}

Received: February 2, 2016

Accepted: February 29, 2016

Online Published: March 25, 2016

doi:10.5430/irhe.v1n2p25

URL: http://dx.doi.org/10.5430/irhe.v1n2p25

Music is joy, an unavoidable human disposition. So, people cannot be without music; if they feel joy, they must express it in sound and give it shape in movement.

(Xunxi, "Discourse on Music," trans. Eric Hutton, 2001)

\begin{abstract}
Recently, music teachers across the globe have had cause to celebrate the accomplishments of many Asian and Asian-American students, who are often immigrants or children of recent immigrants. American and indeed international music undergraduate and graduate programs currently depend on Asian students to fulfill enrollment projections. Many music schools have sent administrators on recruitment trips to China or are holding auditions there. East and West have become musically intertwined through the significant participation of Asian or "Oriental" people in Western classical music, despite deeply dissimilar treatments of harmony and rhythm in traditional Asian music. It has been noted by past scholars that "students from different cultural backgrounds may approach the entire musical experience from divergent points of view. Such a difference, if it does exist, would necessitate a much more detailed consideration of not only choices in music teaching materials, but also activities, strategies, and goals for music learning." (Morrison, Yeh 1999) We argue that teachers must become aware of the cultural differences in learning music, especially in approaching Western classical music: language, emotional responses, etc. in order to be effective with different constituencies. Drs. Hao Huang and Tatiana Thibodeaux have been visiting faculty at the College of Arts in Xiamen University over the past several summers 2012-15, and we would like to share some experiences and insights with our teaching colleagues.
\end{abstract}

Keywords: teaching methodology and approach, music development, music lessons, music school, performance practice

\section{Understanding the State of the Piano in China}

Recent articles in the Asia Times and The Independent assert that approximately thirty-six million Chinese children study piano today, compared to 6 million in the United States (Becker 2004) (Spengler 2008). Another article in the Philadelphia Inquirer notes that another 50 million children in China study the violin and that "Chinese parents urge their children to excel at instrumental music with the same ferocity that American parents push theirs to perform well in soccer or Little League" (Lin 2008). Indeed, Robert Sirota, the past president of the Manhattan School of Music, contended nearly a decade ago as quoted in the New York Times,

I honestly think that in some real sense the future of classical music depends on developments in China in the next 20 years. They represent a vast new audience as well as a classical-music-performing population that is much larger than anything we've had so far. You're looking at a time when, maybe 20 to 40 years from now, Shanghai and Beijing are really going to be considered centers of world art music. (Wakin 2007)

Supporting this conviction, the New York Times has asserted that "with the same energy, drive and sheer population weight that has made it an economic power, China has become a considerable force in Western classical music... The Chinese enthusiasm suggests the potential for a growing market for recorded music and live performances just as an aging fan base and declining record sales worry many professionals in Europe and the United States." (Kahn and Wakin 2007) 
The BBC News has estimated that around four million professional musicians ply their trade in China. (Griffiths 2005) It is clear that the Chinese government has invested hundreds of millions of dollars in Western classical music institutions and concert halls. West Australian Symphony Orchestra Chief Executive Keith Venning opined, "My view... is that they've built these fantastic concert halls and they're now saying to the people 'we've built these halls, now come and use them." (Appleby 2006) Hong Kong music journalist Ken Smith asserted that "China is the sole remaining growth market for classical music... You see new concert halls being built and hundreds of thousands of young musicians who want to make a living." (Druckenbrod 2009) Recently in Beijing, the National Center for the Performing Arts, a colossal titanium-clad dome completed in 2007 has been described by its president Chen Ping as "a concrete example of China's rising soft power." (Ross 2008) The buzz has grown so loud that even The New York Times suggested that "The government has a complex bordering on mania when it comes to building concert halls." (Kahn and Wakin 2007)

And yet, these facile portrayals of China as a Western classical music-crazed society fall short of reality. Amongst most of the music students that we encountered in China over several summers, the overwhelming majority were female. When we asked about the paucity of male pianists, we were told point-blank that their parents were very concerned about how the males would do well financially in their future careers, and that classical Western music seemed a risky bet at best. After all, pianist Tianshu Wang observes, "Yes, the piano is very foreign and new to my country's culture. The first piano was brought to China by an Italian missionary. The beginning of Chinese composition for piano dates from around the time that Russian-born composer and pianist Alexander Tcherepnin came to China. (ca 1930s)" Wu goes on to observe, "When the piano was brought into China, it was viewed as something high-class. Intellectuals and well-connected individuals would have been the most likely people to be exposed to the piano at that time." (Tuttle 2012) Furthermore, there may be a more utilitarian motivation for parents to encourage their children to learn how to play Western classical music at a high enough level to enter competitions, "Parents are putting more emphasis on preparing students to get high test scores and win competitions than on the overall quality of the education. The student's achievement record determines whether or not he or she can progress into high school and beyond." (Fink 2001)

How can one define the difference between Western and Chinese music educators, given different cultural and historical boundaries? Chinese pianist Xiayin Yang has shared,

Even though her Chinese teachers were Western-trained, she's noticed a fundamental difference in approach now that she's come to the United States: "In China, the teacher is dominant, 200 percent. Over here, the teacher has 70 of dominance; the student has the rest. That's the difference, good or bad." ...Is that kind of rigor better than the freer system in the States? "It was good for me," she says. Starting with "constant intensive training" at a young age is crucial. The same training at a later age does not produce the same effect: "I'm learning more and more slowly because I am getting older. I do feel the difference." (Rabinowitz 2008)

Li Delun, The China National Symphony's long-time conductor and a rare example of a Western-trained musician who survived the Cultural Revolution, has gone on record to state "If there wasn't any classical music, there wouldn't be any modernity." (Becker 2004)

\section{Western Music in China}

For China, to begin to understand the present, one must recall the past. Hence a review of history: "the influence of western music in China can be traced back to the $16^{\text {th }}$ century, when the first Christian missionaries arrived. At the end of that century, the Jesuit Matteo Ricci (1610), one of the most influential Italian missionaries, bought a harpsichord to China." (Spence, 1984) He arrived in Macao in 1582, later going on to Beijing in 1601 where he presented it to Emperor Wanli. (Spence 1984) Diego Pantoja, a young priest who accompanied Ricci, taught four of the emperor's eunuch musicians to play the harpsichord and composed eight songs in Chinese for the entertainment and edification of the emperor (Spence 1974) The Qing Dynasty Emperors Kangxi and Qianlong were also presented with harpsichords and enjoyed brief encounters with Western music, but these were restricted to imperial court entertainments. It was only in the nineteenth century, after European and American power forced an Open Door policy for Westerners onto a debilitated Qing Imperial China, that China was flooded with thousands of missionaries with pianos in tow for banging out hymns to save heathen Chinese souls. Western music had gone public in China.

Let's fast forward to the $20^{\text {th }}$ century. Under Communist rule, two opposing groups articulated positions vis-à-vis the modernization of Chinese musical culture. They shared a disregard for China's traditional music as a hopelessly old-fashioned remnant of feudal culture, a tool for reactionaries. The first group was aligned with Russian Soviets and solidly pro-Western classical art music, holding that China would become a modern state once it fully 
participated in international musical culture. European music should be emulated because it is scientific, as evident in the advanced technology of its musical instruments, their precise tuning, the use of harmony and the association of this music with scientifically advanced nations. The other group held that music is modern only when it serves revolutionary causes. These populist musicians were interested not in European art music but only in its techniques, that would serve to update China's own instruments and singing style, adding harmony as they made music to mobilize and modernize the peasants and workers of the Chinese nation. Their position prevailed during the Cultural Revolution. The increasingly powerful People's Liberation Army promoted populist national music performed by its Jinan Military Region's Vanguard Song and Dance Ensemble, that inspired one fellow at the Academy of Sciences to publicly repudiate the European classics that he once loved: "If you listen to more western bourgeois classical music, it slowly muddles your class viewpoint for understanding problems." (Ma 1965)

Yu Huiyong of the State Council's "Culture Group" ascended to the position of Culture Minister in charge of concert programming immediately after the final throes of the Cultural Revolution. Under the pseudonym of "Chu Lan", he argued that the tradition of European music from the late eighteenth and nineteenth centuries is associated with the emergence of the bourgeoisie and is therefore a germ that encourages bourgeois sentiments. Concomitantly, European classical music is based on a theory of human nature that maintains that art can transcend class. Beethoven was held to be a particularly menacing musical humanist. (Chu 1974) Hence, any visiting professor who engages in teaching Western classical music to Chinese piano students may find him or herself embroiled in a controversy over self-identity that goes to the heart of what it means to be a modern Chinese. How does an outsider cope?

Adding to complications is how traditional music is conceived of in China. As recently as 1998, Karin Hallberg acknowledged, "When we say 'traditional' to the Chinese, they think of their traditional instruments (pipa, erhu, etc.). Traditional music is very strong, present, and passionate in China. Their traditional music spoke to their history, poetry, artistry and musicality." (American String Teacher 1998) Li Delun, of the Central Philharmonic has established a strong counterargument, stating that "people need this product of the West to liberate their cultural thinking from 2,000 years of feudalism." Li has taken spreading classical music in China as his mission." (Wang 1987) Beethoven's music, says $\mathrm{Li}$, is of great use in opposing feudal thought, struggling for human rights, and liberating the individual. (Renmin Yinyue 1980)

\section{Music Education in China}

Let's turn to a history of music education in the People's Republic of China. Post 1949, "music in schools 'was and is ever didactic', sharing similarities with other aspects of Chinese education." (Perris 1983) In "On the Correct Handling of Contradictions among the People", Mao Zedong (1893-1976) articulated the central aim of Chinese education to the present day that it should enable everyone who received an education to develop morally, intellectually and physically and become a worker with both Socialist consciousness and culture (Mao 1957). Communist China promoted "a strong revolutionary orientation in the development of music as political propaganda" (Ho 2003). Mao's idea of education harmonized with Chinese tradition "as fundamentally moral-political, and as something which goes on throughout life and involved all that man does" (Price 1979).

By 1979, China's Ministry of Education had identified music as an indispensable subject for lessons in morality for youth (Ma 2002). The policy states that the primary task of moral education is to foster zealous love for the motherland, social ethics and civic values as stated by the Editing Group of the Arts Faculty Teaching Materials, Beijing Physical Education University in 2005. Music contributes towards an aesthetic education that will heighten morale, courage and confidence in social progress. One of the great ironies of modern Chinese politics is that the Confucian identification of music with statecraft has been perpetuated by the revolutionary Chinese Communist Party. Despite their condemnation of Confucian feudal thinking, Chinese Communists have always shared the Confucian belief that music and art is politically relevant.

In 1986, the Chinese Musicians Association held its first National Music Education Conference, where the function of music education and its role was seriously discussed. The need for music education was affirmed as integral to developing students' moral, intellectual and physical capacities. As a result, in 1989 when the State Education Commission was restructured by establishing separate Social Science and Arts Education Departments, focused management of arts education was introduced in primary and secondary schools. In 1994, one of Jiang Zemin's earliest actions as President of the People's Republic of China was to dictate to the State Board of Education to strengthen high school arts education by setting up "music appreciation" classes. All books used for music appreciation reaffirmed a very traditional Chinese value that good music creates good morals. Symphonies were said to be better than popular music, warranting state support because symphonies will make their listeners into better people. (Kraus 1989) 
Music education is regarded as a controlling factor in harmonizing human beings into the well-ordered Confucian society (Ho 2003). Moreover, the nationalistic fervor encouraged by the Chinese government is not limited to traditional Chinese music, Chinese folk songs, and revolutionary songs, but also extends to foreign composers of nationalist music. "The movie $A$ Song to Remember, written by Sidney Buchman and directed by Charles Vidor (1945), was produced during World War II to romanticize Frédéric Chopin's patriotism. This has been used in the $21^{\text {st }}$ century in the PRC to teach Chinese students to love their motherland. After the students of Suzhou University saw the film they were inspired to produce a book of "more than 3000 articles' to express their patriotic feelings." (Li 2004) This exhibits the still potent power that Western classical music holds for Chinese youth. As noted by Western classical music conductor Juanita Hauk, "The Chinese seek international status by identifying with classical music. In acknowledging their own isolation and to express cultural nationalism, vigorous efforts are made for Chinese musicians to win prizes in the international music competitions." (American String Teacher 1998) China's political and economic growth affects all aspects of education, including music.

"The development of a market economy has resulted in students' materialist and individualist value orientation becoming more and more apparent... Critical thinking and personal value judgements are stressed in contemporary education for their importance for students' life-long learning... Whilst individualist values are growing in China today, collective socialist, ethical and family values are still emphasized in moral and music education. Chinese have a long-term strategic task to strengthen and improve ethical and moral education among Chinese youth." (Ho 2010) It's fairly obvious that we as visiting music faculty have to recognize and work within these overall goals for students, not simply lose ourselves in Western notions of art for art's sake. Our purpose cannot be simply to promote pleasure. That is not the purpose of teaching music in higher education in the People's Republic of China. We should also consider ourselves privileged to be at the forefront of the Western classical music struggle for survival. As Louis Bergonzi has proposed, "The need for meaningful, rich understanding of our world and its people has never been greater. By learning about people from another culture, we learn not only about them but also about ourselves." (American String Teacher 2001)

\section{All Hail the Conquering Piano}

One cannot not ignore the special appeal that pianos have held for many Chinese families. Pianist Tianshu Wang contends, "Nowadays with the rapid financial development in China, families want to provide the best possible education for their children. Studying a musical instrument has become fashionable and essential. Many families choose the piano, and they can afford the instrument and the lessons. As with Lang Lang's family, 'piano parents" can be extremely devoted." (Tuttle 2012) Juanita Hauk has elaborated, "With a shared commitment to an urban-based modernization of Chinese society, there is a strong emerging urban middle class culture... The re-emergence of an urban middle class, with thousands of small enterprises blossoming, has offered new skills to a market-oriented economy. Along with the rising incomes of the Chinese family the solitary child is mostly likely to be indulged with piano." (American String Teacher 1998b) This focus on the piano in China is corroborated by an article in the Independent that selects South Korea, Japan and China together as producers of 90 percent of the world's pianos. (Becker 2004) Why have these nations taken to Western classical music with such a passion when other cultures in India, South Asia or the Middle East have not? Answers may be found by tracing cultural roots--in China's case, by reconsidering the Confucian roots that also strongly embrace Japan, Korea and Taiwan.

\section{Confucius and Music}

The story goes that after Confucius studied the Guqin from the master musician Shi Xiangzi for a few days, his teacher said his performance was "good". Confucius, however, was not satisfied with his progress and kept training for a longer time. After practicing for another couple of days, his performance was rated as "excellent" by Master Shi, but Confucius still did not believe that he had adequately studied the music because he could not feel the spirit of the melody when he played the Guqin. It is not until he finally grasped and fulfilled the inner spirit of music that Confucius became content. His perseverance won the genuine respect of Shi Xiangzi. Even today, Confucius's edict of "Be insatiable in learning" is still regarded as axiomatic by many Asian people.

Not only was Confucius an advocate for Music Education, but he was also an avid practitioner as teacher and student. Confucius lived in an uncertain feudal era of transition, when central governments had fallen into disarray. Ritual ceremonies had been fallen into disuse or forgotten, and music had become a sensual entertainment. In response to these conditions, Confucius regarded music education as a way to address the social and political problems of peaceful coexistence. The primary focus of Confucianism was to construct the moral education of a citizen or ruler, so that the state could in turn be governed by moral virtue (Lawrence, 2000). The ruling elite were to be indoctrinated in the five virtues: self-respect, kindness, honesty, perseverance and benevolence. The rationale of 
Chinese music education involved moral education as a way of leading people to follow virtuous ways of living. Confucius integrated songs and music in his curriculum to develop the sensibility and ethical commitments of his pupils (Kim, 2006). In the Analects, he is supposed to have said, "A man who is not Good, what can he have to do with music? (Confucius, tr. Waley 1938)

Westerners may be inspired to respond with a wordier quote from another bard from two millennia later,

"The man that hath no music in himself,

Nor is not mov'd with concord of sweet sounds,

Is fit for treasons, stratagems, and spoils.

The motions of his spirit are dull as night,

And his affections dark as Erebus.

Let no such man be trusted. Mark the music." Shakespeare, The Merchant of Venice (Act 5, Scene 1)

"The effects of western colonialism and neo-colonialism are observed in many countries of the world, where Western models of teacher training have been adopted, and curricular emphasis is on Western music. Countries such as Ghana, Japan, Korea, and China have adapted Western systems to fit their own cultural frames." (Royse/Addo/Klinger/Dunbar- Hall/Sheehan, 1999) However, after teaching in China for a number of summers over several years, we have become more aware of how basic knowledge of Western repertoire and practice performance is incomplete. Due to the official ban on Youtube and other social media sites in the arts, the aural component of understanding the past is often missing. In China, students cannot easily go online to find performances that they are largely unaware of. So perhaps the Western models of teacher training have been officially adopted, but that has very little to do with life and learning "on the ground." This is why we keep returning to the PRC, because they actually need real live people to convey and communicate basic knowledge about what is necessary to become aware of in the area of Western classical music. Avid practitioners may be in abundance, but cultural and musical experts remain scarce and those who visit can still make important contributions.

Given patience and historical awareness, there are ways for teacher and student to meet. In emphasizing the musical interpretive side of music performance, we found we could open awareness while connecting with the deepest levels of self-identity. After all, Ms. Wang has gone on to acknowledge, "What does she like about being a pianist? 'So many things. It's difficult for me to explain, but I see myself through the piano. I am lucky that I can express myself, speak about myself very clearly through the sounds of the instrument." (Rabinowitz 2008) Traditional Asian culture prizes the study of past works that epitomize classical principles. Involvement with Western classical music presents the prospect of committing to memory exemplary compositions through disciplined practice and intense focus. Acquiring this expertise by studying under an individual master/mistress corresponds to Confucian scholarly tradition, that also values music study as an essential way to train the mind. The apprentice to master approach to gaining knowledge in China has been long established. Also, numerous Asian cultures value a meticulous approach to skill acquisition, which often involves rigorous parental involvement in a practice regimen, as well as due veneration of the master.

How can understanding some ancient Confucian precepts about music pertain to modern Western music teachers, when they interact with Asian/Asian-American students? To work against the historical residue of imperialism and colonialism, teachers should try to avoid reinforcing a cultural hegemony--it is appropriate instead for Western music teachers to work towards comprehending how Asian cultural heritage affects student attitudes towards music. Sharing common values held by Eastern and Western musical philosophies can assist both teachers and students to develop a mutual understanding of how the work they do in music is meaningful. Western classical music has been relegated in popular culture to being a luxury item for a privileged few. Its future will be determined by current music students, many with Asian cultural backgrounds. Are we abandoning the moral and ethical power attributed to music by the ancients from East and West, when well-intentioned music advocates base their attempts to value music study by trumpeting the "Mozart effect"?

\section{Observations on Teaching Piano in Xiamen, PRC}

During our teaching of piano students in Xiamen, we found that there were some very significant impediments in talking about interpretation of music. Not only was there a surprising lack of knowledge about the lives and minds of composers, but often piano-playing was approached as skill-acquisition absent much cultural context. As pianist Xiayin Wang has noted, "But the real problems are not physical: 'I should not blame it on my hands. Patience and a lot of practice will solve the problem.' Rather, the abiding problems are interpretive... 'Right now, I'm dealing with 
Scriabin. I have an issue with him, sometimes I can't understand why things are written like this or that. I try to make it make sense, but sometimes I don't feel that I can grasp what he is trying to say. That happens a little bit with any composer, it depends on what piece."' (Rabinowitz 2008)

In fact, this was most notable in Baroque and Classical repertoire. We found most students to be shockingly uninformed about early music performance practice, although early keyboardist Masayuki Maki has declared, "The students were extremely happy to take the class and eager to immerse themselves in the world of Baroque expression. The faculty was also glad to have a specialist in early keyboard music teaching their students. They wanted their students to know more about the history of music and the development of historical instruments." (Maki 2008) It seemed to us that most Chinese student pianists had never encountered harpsichord playing, even on the Internet.

Nearly twenty years ago, an American string delegation visited the PRC and made interesting reports on the state of music education in China. We would like to respond to how things have and have not changed. It was stated, "Typically each student is expected to memorize one piece of music each week and they are tested each month at a recital. Memorization is a key teaching element." (American String Teacher 1998) We did not find this to be so in Xiamen University. In fact, time and again, we found ourselves imploring students to let go of their xeroxed scores after months of study to play by memory. It seemed to us that many students clung to the printed scores for security, but did not challenge themselves to undergo the process of internalization involved in thorough memorization of music. The challenge to perceptively decode a score is universal, but can be particularly difficult for Chinese students. Perhaps the general focus on competing to display technical virtuosity reinforces a "wild horse galloping" attitude that overrides thoughtful engagement with the music. After assiduous inculcation of muscle memory, the additional effort to convey detailed emotional content may seem irrelevant and burdensome. Fingers can take over the brain's main capacity to process; these digits may run ahead of mental command in chaotic disorder. Many Chinese students and their primary teachers fail to realize that producing and revealing a beautiful musical message involves more than just ingraining pure muscle memory.

Certainly, the Arts College at Xiamen University cannot be regarded as a cultural backwater. It is regularly ranked in the top 25 universities in the PRC and has been selected as top research university in the PRC awarded Project 211 and 985 grants, which aim is to promote China's higher educational competitiveness by establishing support of leading disciplines that will be globally competitive. In fact, while we visited during the summer 2015, guest professors from the Cincinnati Conservatory of Music and the Juilliard School were also present on campus to teach XU music students. And yet nearly two decades later after his initial statement, we were reminded of Jonathan Sturm's observations: "At smaller more outlying institutions, the emphasis is not much on performance but on teacher training. Here the emphasis, we discovered was on piano and voice, with strings as a distinct secondary instrument." (American String Teacher 1998) Through our own experiences, this situation has not changed much. The ambitions of the most advanced piano students seem to involve coming back to Xiada after graduate studies abroad to eventually teach as piano faculty.

We found that it is also important to resist exoticizing Chinese students as paragons of self-control and discipline. Abraham Chavez wrote about them, "In all three levels of education, the learning procedures seemed to be based on the strength of Chinese traditions: order, discipline, focus, dedication, obedience, respect, perseverance, methodology, tirelessness." (American String Teacher 1998b) This simply does not hold true for all the Chinese students we worked with. To be sure, many were enthusiastic, receptive, hard-working. Yet one should not romanticize that all Chinese students are such. We encountered a fair amount of resistance, especially to musical suggestions about phrasing or expressive nuances that they had not encountered previously in their studies. Also, a certain tentativeness and rhythmic stiffness often pertained in student responses to suggestions. The key was to allow them to try several times, sometimes after demonstrations. Pedagogically, we also found that invoking metaphors often helped to loosen students up enough to respond with flexibility and élan.

This leads us to a discussion of what contributes to teaching effectiveness in China. It has been observed by past instructors that “... students from Hong Kong and China made metaphorical comments more often than analytical, and students from the US made analytical comments more frequently than metaphorical." (Morrison, Yeh, 1999) This tendency proved to be directly compatible with the more metaphorical suggestions made in masterclasses with our college age Chinese pianists. They seemed to be more responsive and open to metaphors that transcended more physical, technical comments that also had to be made to alter their technical approach. Frequently, sound was a crucial problem for most -- they seemed unaccustomed to listen for quality of singing tone. The reason singing tone is so important is that it also helps us tell a story, a narrative through which the phrases and music flows. The lack of attention to tone quality may be related to the state of the practice pianos available, which were nearly uniformly in 
dreadful condition. The efforts of piano technicians were focused on performance instruments that were kept in more climate controlled environments than the practice pianos.

Beyond critical aspects of sound and tone production, we also found that we had to find ways to connect directly to our piano students. Chinese students are trained to be respectful, but veneration does not help in developing performance skills. Gan Wang has observed, "The teachers were very shy and reluctant to come up and join the activities. So I decided to play the game with the brave few. They started to giggle when we jumped around to meet the new partner." (Hamilton 2005) This underlines the importance not only of breaking cultural barriers, but social boundaries. It is important for Westerners to recognize that most Chinese are conditioned to be shy and reserved in public, and to come up with strategies to encourage more relaxation in the people they work with. Shuyi Chen has noted: "First, she wanted students to listen and respond to different instrumental timbres; second, she wanted students to use their imaginations and develop creative-thinking skills." (Hamilton 2005) This relates to our efforts to "break the ice" by appealing to metaphors and the imagination, to try to relate Western classical music to what young Chinese aspire to live and produce.

Also, teacher-student interactions often have a different flavor in China. As mentioned earlier in this article, the relationship between student and teacher in China is often akin to that between apprentice and master. As Gong-Wei Don (Steve) has noted: “...American teachers prefer informal ways to help students; Chinese teachers would like to apply more formal ways to instruct. The relation between you and Chinese students is very close, just like friends, while the relation between Chinese teachers and students is very serious, just like parents to their children." Fran noted other differences: "As teachers, Karen and Roger are rich in facial expression and gestures, which Chinese teachers seldom use. They never hesitate to demonstrate with body language in order to offer a vivid and clear explanation to students. They never forget to say 'congratulations' to their students whenever they make some achievement, even if a very little improvement." (Iglitzin 1998) This relates to our own spontaneous encouragement and praise of students, as opposed to conventional Chinese reserve. We suggest that building a healthy musician is akin to building an aesthetically pleasing building. Without ensuring a strong positive foundation, it becomes nearly impossible to cultivate the confidence for freedom of expression and self-esteem so vital to successful performances. Nevertheless, it is important to recognize and respect cultural differences in teaching.

We should also acknowledge the indispensable help we received from our own interpreters at Xiada, Gong WanJing (Grace) and Tang Ling Jing. Working with them was definitely rewarding, yet challenging. Certainly there were challenges in trying to convey the meaning of words or phrases that are evocative which can be obscure in any language. But our interpreters' unfailing good will and politeness smoothed over many potentially awkward moments. As obliging as our translators were, we had to consider some unconventional ways of delivering our messages. Physical demonstration, facial expressions, and variety of gestures were also necessary to communicate effectively. In addition, western pedagogues must remember to be patient with the process of translating and pause for students to reflect on every word they hear. Interestingly, we found ourselves in accord with a fellow teacher in China's statement, "I found that I tended to talk too much. For example, I would make a statement, then barely waiting for it to be translated, I'd jump in again as soon as possible. I had to learn to wait and try to first observe the student's reaction to each of my sentences." (Iglitzin 1998) I think that insight relates to good teaching. Too often as academics, we're living and speaking in our own little worlds without taking the time to observe how the student is responding. It was helpful to become more aware of that issue.

En fin, what we tried to convey to our Chinese piano students was a joy in expressing themselves in music, albeit in an informed and organized way. As Joel Schoenhals is quoted as saying, "What you want is for the music to be alive and improvised in feeling-- spontaneous... what I strive for is for the music to sound alive. You are also so right that one of the tricks of creating a magical or great performance is managing a sense of large-scale flow along with terrific moment-to-moment attention to detail." (Clarke 2015) This goes to the heart of what we are trying to impart to the Chinese students, who often play too woodenly, by rote. It's almost as though they are not really putting much of themselves into the task of learning the motivations behind the notes. The term freedom of expression is used a lot in the States, but it was often absent in most of piano playing we heard in Xiamen. Not always! Sometimes it's almost the opposite, we had to restrain some students to reconsider and think about what they're doing instead of galloping around like a wild horse. Unbridled enthusiasm is sometimes hazardous to making great art!

On many occasions students would beg us to suggest quick fixes of challenging passages or recipes for consistent performances, free of memory slips or mistaken notes. We found ourselves responding with compelling arguments advocating "intelligent" practice that did not involve mindless repetition, and we advocated paying more attention to the score. Such strategies help to eliminate the self-defeating circle of repeated habits involving the same frustrations, the same mistakes, and the same limitations. As musical performers, we strive not to become calloused, heartless, anxious, and impatient, and, eventually, willfully deaf. 


\section{Cadenza}

A welcome irony may be that exploring ancient Chinese attitudes towards music can regenerate pride of purpose for Western music educators. The current state of classical music education in the West is mixed at best, with fewer and fewer resources directed to it, while countries like China are trying to emerge by actively supporting it. Gong Wei Dong (Steve) asserts that "Music is a special kind of language beyond the country borders, especially classical music, which is shared by all the people under the sun." (Iglitzin 1998) We need to affirm that music is valuable for itself alone, as a unique art form. In an age of perfect digital recordings, why should we encourage students to make imperfect performances? As Western musicians, we are challenged to empathize with Chinese pianist Xiayin Yang: "Technique serves the heart. Technique serves the music. It cannot be any more important. You have to have technique to be able to express, but if it's just technique, it's going to murder the audience." (Rabinovitz, 2008) Surely we must find an answer in a viable aesthetic philosophy which draws from both East and West. Music is indisputably a transitory art, coming alive only during the moments of performance. It requires active participation in the here and now, challenging musicians to create and recreate beauty in each and every performance.

"Music is a living thing, not a fixed medium--it is subject to how performers interpret it." This sentiment has been a familiar homily of Western classical music teachers, but it is also a value in Chinese traditional music as expressed by Shi Tan, professor of the erhu, the two-stringed Chinese violin, at the Shanghai Conservatory of Music. He finds himself facing the same problems of reinvigorating and renewing a venerable musical tradition as we in the West do. Thus West and East can meet, with classical music that exists partly to remind that new music is not necessarily the best -- it is merely the most recent genre. Western and Asian art musics are both lovingly cherished cultural traditions that have are reconstituted through the most rigorous professional training and intensive artistic dedication. If we as musicians contain the promise of music, what better way to keep that promise than to share with future generations ways to reinterpret the classics?

Demonstrating the potent cross-cultural power of music, world-renowned pianist Yundi Li was initially drawn to the piano as a individual child experiencing a chance encounter of hearing someone practicing the piano, after spending two years playing the accordion: "I had never heard a piano before.... And this sound, with its rich range of color, was instantly very special for me. I hung outside the window for half an hour, drinking it in." (Church 2010) He has been appointed "image ambassador" for Super Boy - China's equivalent of American Idol. "They want to hold me up as an example of what Chinese children can achieve, so I play for them, to show that the dream is not so far off... with talent and hard work, your dream can come true." (Church 2010)

\section{References}

American String Teacher. (1998). String Education in China: An American Delegation Reports on Historic Visit, $48(3)$ 36-9, 41.

American String Teacher. (1998b). String Education in China: Part 2--Social, Political, and Cultural Effects on String Teaching, 49(3), 42-46.

Appleby, R. (2006). China - the saviour of classical music? Music Council of Australia. June. Retrieved 17 December 2010 from www.mca.org.au/.../China-the\%20Saviour\%20of\%20Classical\%20Music.pdf

Becker, J. (2004, October 30). After years of silence, China's growing passion for western classical music sounds vibrant note. The Independent, Foreign News, p. 39.

Chu, L. (1974). Grasp the essence, deepen the criticism [reprinted as: criticize the revisionist viewpoint in music]. Peking Review, 17, 18-19.

Church, M. (2010, March 7). Yundi Li: 'I think I'm not a normal artist'. The Independent on Sunday, Arts \& Leisure, $27-30$.

Clarke, C. (2015, Nov./Dec.). Pianist Joel Schoenhals on Schubert, Schuman, Chinese Music, and Beyond. Fanfare The Magazine for Serious Record Collectors. 38(2), 212-220.

Confucius. (2001). The Analects. (A. Waley, Trans., Original translation published 1938). New York: Alfred A. Knopf Inc.

Druckenbrod, A. (2009, June 28). China captures music world's ear; once banned, classical music explodes in popularity among Chinese. Pittsburgh Post-Gazette, Arts \& Leisure, p. E-1.

Fink, L. (2001). String Teachers in China. American String Teacher, 51(2), 68-73

Griffiths, D. (2005). Classical music takes Chinese stage. BBC News. 1 September. Retrieved 11 December 2010 from http://news.bbc.co.uk/2/hi/asia-pacific/4200906.stm 
Hamilton, H. (2005, October). From a Teaching Adventure in China. Echos, 24-27.

Ho, W. C. (2003). The sociology of China music education: Westernization and social transformations, 1895-1949. History of Education, 32(3), 289-301.

Ho, W. C. (2010). Moral education in China's music education: Development and challenges. International Journal of Music Education, 28(1), 71-87.

Iglitzin, K. (1998). Teaching with Interpreters (in China). American String Teacher, 48(3), 48- 51, 53.

Kahn, J., \& Wakin, D. (2007, April 3). Classical music looks toward china with hope. The New York Times, p. A-1.

Kraus, R. (1989). Pianos and politics in China: Middle-class ambitions and the struggle over western music. New York: Oxford University Press.

Lawrence, R. (2000). Education in China: Preparation for citizenship. Asian Affairs, 31(3), 274-284.

Li, D. (1980, October). Li Delun tan woguo jiaosizng yinyue shiye [Li Delun Discusses the Task of Our Nation's Symphonic Music]. Renmin Yinyue, 187.

Li, L. (2004). Education for 1.3 billion. Beijing, PRC: Foreign Language Teaching and Research Press \& Pearson Education.

Lin, J. (2008, June 8). China's 'piano fever'. The Philadelphia Inquirer, p. A-1.

Ma, D. (2002). Ershi shiji zhongguo xueshao yinyue jiaoyue (Chinese school music education of the $20^{\text {th }}$ century). Shanghai: Shanghai Education Publishing Company.

Ma, T. (1965, March 4). Xiyang zichanjieji yinyue dui wo de duhai [I was poisoned by the bourgeois music of the west]. Self-translation. Guangming Ribao, pp. 10-12.

Maki, M. (2008, Winter) Playing in China. Early Music America, 64, 61-2.

Mao, Z. (1957). On the Correct Handling of Contradictions among the People [Speech at the Eleventh Session (Enlarged) of the Supreme State Conference. Comrade Mao Tsetung went over the verbatim record and made certain additions before its publication in the People's Daily on June 19, 1957.]

Morrison, S. J., \& Yeh, C. S. (1999, Spring). Preference Responses and Use of Written Descriptors among Music and Nonmusic Majors in the US, Hong Kong, and the People's Republic of China. Journal of Research in Music Education, 47(1), 5-17

Perris, A. (1983). Music as propaganda: Art at the command of doctrine in the Peoples Republic of China. Ethnomusicology, 17(1), 1-28.

Price, R. (1979). Education in modern China. London, Boston MA \& Henley: Routledge \& Kegan Paul.

Rabinowitz, P. (2008). Discipline and Heart: A Conversation with Xiayin Wang. Fanfare, 31(3), 30-33.

Ross, A. (2008). Symphony of millions: Taking stock of the Chinese music boom. The New Yorker, 84(20), 84.

Royse, D., Addo, A., Klinger, R., Dunbar-Hall, P., \& Campbell, P. S. (1999). Comparing Music Teacher Training Practices around the World. Journal of Music Teacher Education, 8(2).

Shakespeare, W., \& Mowat, B. (Eds.) (1992). The Merchant of Venice. New York: The Folger Shakespeare Library, 225.

Spence, J. (1974). Emperor of China Self-protrait of K'ang-his. New York: Knopf.

Spence, J. (1984). The memory palace of Matteo Ricci. New York: Viking Penguin.

Spengler. (2008). China's six-to-one advantage over the US. The Asia Times, 2 December. Retrieved 11 December 2010 from http://www.atimes.com/atimes/China/JL02Ad01.html

Tuttle, R. (2012, March/Apr). Pianist Tianshu Wang: Building Musical Bridges. Fanfare, 35(4), 164-167

USA Today. (2008, February 24). China could give classical music a boost. Life, p. D-1.

Wakin, D. (2007, April 4). Increasingly in the west, the players are from the east. The New York Times, The Arts, p. E-1.

Wang, Y. (1959). Xiandai zichanjieji fandong yinyue liupian jianajie [A brief intgroduction to contemporary bourgeois reactionary musical schools]. Self-translation. Renmin Yinyue, February, 37-38.

Xunxi. (2001). Discourse on Music, trans. Eric Hutton. In Philip J. Ivanhoe and Bryan W. Van Norden (Eds.), Readings in Classical Chinese Philosophy (2 ${ }^{\text {nd }}$ ed., 2001, p. 285). Indianapolis, IN: Hackett. 